\title{
Do Lunar Cycles Influence Shark Attacks?
}

\author{
Erich Ritter ${ }^{1, *}$, Raid Amin ${ }^{2}$ and Aletheia Zambesi ${ }^{2}$ \\ ${ }^{I}$ Shark Research Institute/Florida Office, 5970 Osprey Place, Pensacola, FL 32504, USA \\ ${ }^{2}$ University of West Florida, Department of Mathematics \& Statistics, 11000 University Parkway, Pensacola, FL 32514, \\ USA
}

\begin{abstract}
One recurring factor seemingly causing an increase in shark attacks is lunar cycles, especially the full moon. However, the potential association between shark attacks and lunar cycles has never been verified. Our results show that a correlation between shark attacks and moon cycles does not statistically exist. With no correlation between shark attack rates-independent of people's activities-and lunar cycles found, we also applied the same statistical procedures to surfer incidents only. The reasoning for narrowing the attacks to those on surfers was as follows: (1) Surfers indicate the best conditions to surf exist during the full and new moon. (2) Surfers are more exposed to shark attacks than non-surfers. However, as with the initial results, shark attacks involving surfers did not show any correlation to lunar cycles, neither did those involving non-surfers. These results indicate that potential triggers for shark attacks need to be studied in a more pragmatic manner, using, for example, mathematic approaches to test for global phenomena and then individual instances, leaving guess work largely aside.
\end{abstract}

Keywords: Full moon, lunar cycle, shark attack, tide.

\section{INTRODUCTION}

For many years, people have looked for factors causing shark attacks [e.g., 1-3]. These factors have largely been linked to basic factors, that is, food conditioning [e.g., 4], mistaken identity [5, 6], and others [e.g., 7]. However, with the exception of some individual events [e.g., 8, 9], none of these broader assumptions have ever been tested [e.g., 10]. Hence, it does not come as a surprise that many of these anecdotal triggers continue to be cited [e.g., 11]. One of the more persistent factors regularly appearing in popular and semi-professional science outlets is the linkage of lunar cycles to elevated shark attack numbers, especially full moon phases [e.g., 11-14]. That the behavior of animals [e.g., 1517] and humans [e.g., 18-20] has been influenced by lunar cycles is known but it has not been scientifically determined if such an effect guides the bite rate of sharks, as well. In this study, we statistically analyzed the effect of lunar cycles on the number of worldwide shark attacks. The idea that moon cycles, especially full moons, were a trigger stemmed largely from a combination of different facts and communal wisdom. First of all and most prominently, incidents occurred by chance on full moon dates but were never compared according to the probability in relation to other days throughout a month [e.g., 10]. Furthermore, some landings of certain shark species-for example, blue sharks, Prionace glauca; makos, Isurus oxyrhinchus; and oceanic whitetips, Carcharhinus longimanus-increased during full moon [21, 22], or sharks, in general, showed activity in relation to lunar

*Address correspondence to this author at the Shark Research Institute/Florida Office, 5970 Osprey Place, Pensacola, FL 32504, USA; Tel: 28609292092120505; Fax: 6099211505; E-mail: erichritter@att.net cycles [23] so that the likelihood of a full moon and sharkhuman interaction relation seemed plausible. It has also been suggested that some prey species avoid activity during a full moon to avoid shark attacks $[24,25]$.

\section{METHODS}

The attacks for the ten years between 2002 and 2011 that were filed with the Shark Research Institute's "Global Shark Attack File" have been evaluated [26]. Although shark attacks are a worldwide phenomenon throughout tropical, subtropical and temperate waters, some areas experience more incidents than others. It could be that more accident prone species frequent those waters or that some areas possess more favorable conditions than others for certain activities like e.g., surfing. Despite that such areas experience more shark attack incidents, these hot spots represent a worldwide distribution thus offering an unbiased approach. As it can be seen in Table 1, the top 10 areas include locations from both hemispheres. Despite the fact that about $50 \%$ of all incidents occurred within US territories for the time examined, such areas should not be analyzed independently since it would 1) reduce the appearance of a potentially small effect making it possibly not recognizable and 2) reduce the analysis to the few months of the year where water temperatures are warm enough for people to enter the sea in that area. Furthermore, it has been shown [27] that e.g., the incident rate of California likely depends primarily on the migration routes of mature female white sharks, Carcharodon carcharias, hence this reflects a one species effect that does not show up e.g. in Florida where other species are involved in incidents [28].

Some cases were excluded from the evaluation e.g., where humans put themselves knowingly in harm's way, i.e., 
Table 1. Percentage of Shark Incidents for the Ten Top Countries Between 2002 and 2011

\begin{tabular}{|c|c|c|}
\hline Rank & Country & Percentage of Global Attacks \\
\hline \hline 1 & United States & 50.3297 \\
\hline 2 & Australia & 8.4615 \\
\hline 3 & South Africa & 3.6264 \\
\hline 4 & Brazil & 2.1978 \\
\hline 5 & Bahamas & 2.1979 \\
\hline 6 & New Zealand & 1.7582 \\
\hline 7 & Egypt & 1.4286 \\
\hline 8 & Reunion & 1.3187 \\
\hline 10 & New Caledonia & 1.0989 \\
\hline
\end{tabular}

Table 2. p-values of the Chi-square Test for Shark Attacks between 2002 and 2011 with Reference to Specified Time Periods Around a new and a Full Moon

\begin{tabular}{|c|c|c|c|c|c|c|}
\hline & $\pm \mathbf{3 d} \mathbf{M f}$ & $\pm \mathbf{4 d} \mathbf{M f}$ & $\pm \mathbf{3 d} \mathbf{M n}$ & $\pm \mathbf{4 d} \mathbf{M n}$ & $\pm \mathbf{3 d} \mathbf{M f} / \mathbf{n}$ & $\pm \mathbf{4 d} \mathbf{M} / \mathbf{n}$ \\
\hline \hline All Incidents & 0.1399 & 0.6326 & 0.1423 & 0.0803 & 0.0153 & 0.0224 \\
\hline Surfers & 0.0531 & 0.3116 & 0.4000 & 0.1133 & 0.0184 & 0.0155 \\
\hline Non-surfers & 0.7543 & 0.9072 & 0.2293 & 0.3140 & 0.2019 & 0.2916 \\
\hline
\end{tabular}

$M_{f}=$ Full moon, $M_{n}=$ New moon, $M_{f} / n=$ Full Moon and new Moon Combined. $\pm 3 d, \pm 4 d=$ Number of days before and after $M_{f}$ and $M_{n}$, Respectively

feeding sharks, fishing for sharks, or spear fishing. The remaining 910 cases were categorized as overall attacks $(910$ incidents), surfing attacks (319 incidents), and non-surfing attacks (591 incidents). Surfing incidents were separated because it is known that the highest waves, the best for surfing, occur around the full and new moon, bringing more surfers to the beaches than at other times. Furthermore, it has been shown that surfing carries a higher risk of being bitten than other beach-oriented activities [28, 29].

Because a correlation between shark attacks and lunar cycles could be tested in different ways, several questions were chosen to be answered: (1) Are shark attack rates higher in number during a full moon (Mf) than for the rest of the month? (2) Are shark attack rates higher in number during a new moon (Mn) than for the rest of the month? (3) Are combined shark attack rates for the full moon and new moon $(\mathrm{Mf} / \mathrm{n})$ higher in number than for the rest of the month? (4) For these previous questions, do the numbers for shark attack rates during $\mathrm{Mf}, \mathrm{Mn}$, and $\mathrm{Mf} / \mathrm{n}$ differ for surfers and nonsurfers?

Since average wave height increases near Mf and $\mathrm{Mn}$ and then decreases again, the actual days of Mf and Mn were expanded to \pm 3 days and \pm 4 days from the actual $\mathrm{Mf}$ and $\mathrm{Mn}$, and the shark attack rates on those days compared to attack rates during the remaining days of the month. The attack rate for any given day $\mathrm{X}$ was defined as the ratio between number of shark attacks on day $X$ to number of times day $\mathrm{X}$ occurred within the studied time period. A Chi-square test for goodness of fit was used to compare the observed shark attack counts with the expected counts should the null hypothesis of equal shark attack rates for Mf and Mn be supported. The same approach was applied to the combined values of Mf and Mn combined (Mf/n).

\section{RESULTS AND DISCUSSION}

The tests of a potential correlation between shark attacks and lunar cycles did not reveal significant evidence (with $p>$ 0.05 ) that shark attack rates were higher during the \pm 3 and \pm 4 days around $\mathrm{Mf}$ or the \pm 3 and \pm 4 days around Mn (Table 2). The same nonexistent lunar dependency was reflected, based on the \pm 3 and \pm 4 period around $\mathrm{Mf} / \mathrm{n}$. The observed proportions of shark attacks for the two time periods, $41.78 \%$ and $55.60 \%$, respectively, were smaller than the expected numbers of $45.76 \%$ and $59.32 \%$. Because the expected numbers are higher than the calculated ones for the chosen times, they confirm the nonexistence of a lunarcycle-induced increase in attack rates.

Although $\mathrm{Mf}, \mathrm{Mn}$, and $\mathrm{Mf} / \mathrm{n}$ did not show any correlation to shark attack rates, some periodicity was displayed when listing daily attack rates for "closeness to Mf" and "closeness to Mn" with day 0 representing a full moon and day 15 a new moon (Fig. 1). It is understood that every "day" between 0 and 15 reflects any day of the week, based on the actual date of the lunar cycle, hence shows a rather constant number of people visiting beaches. Although Mf and Mn show elevated shark attack rates, these increases were not limited 


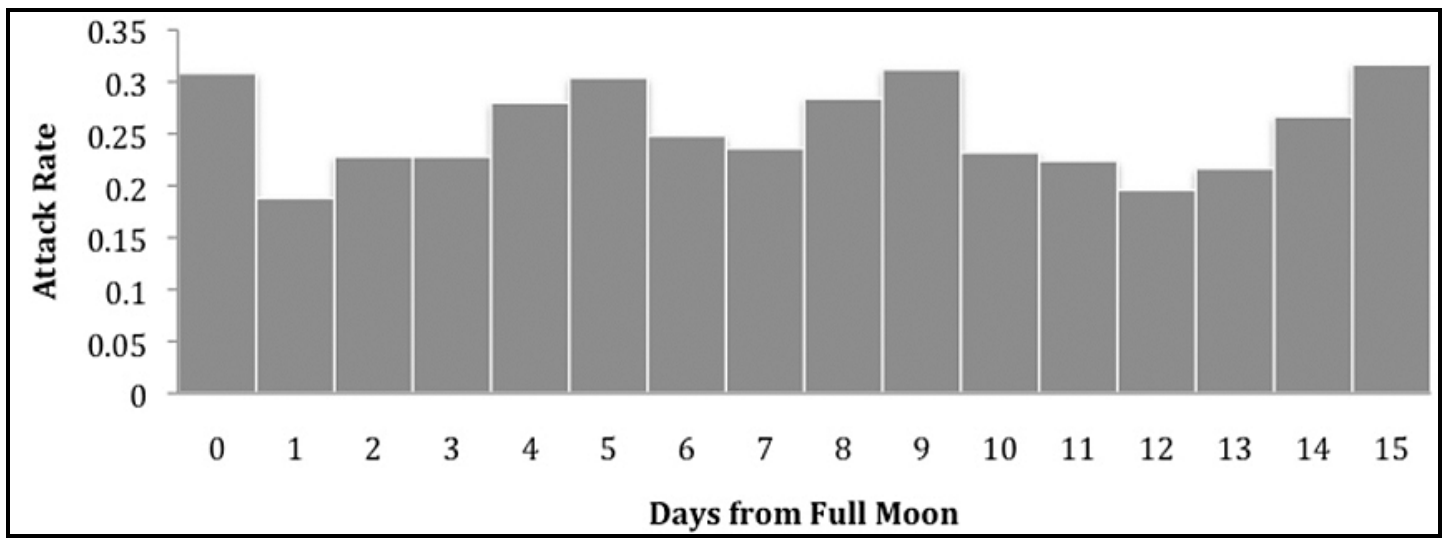

a) all incidents combined

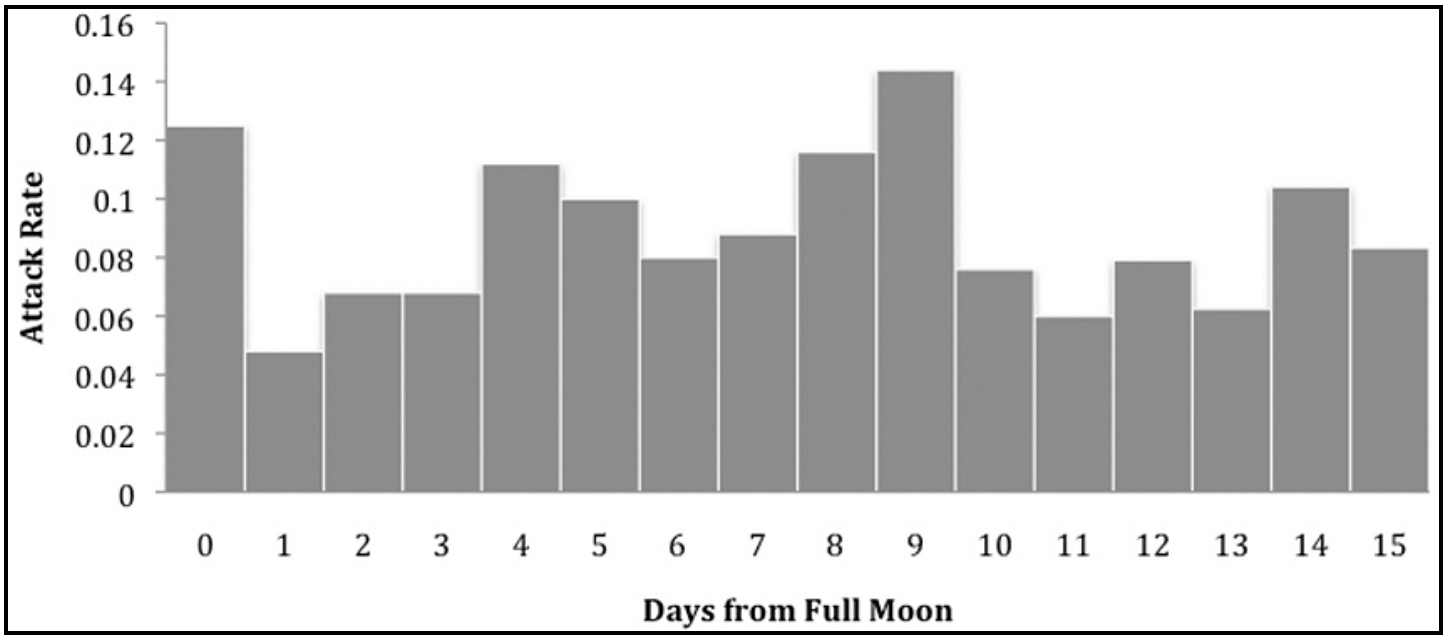

b) surfers only

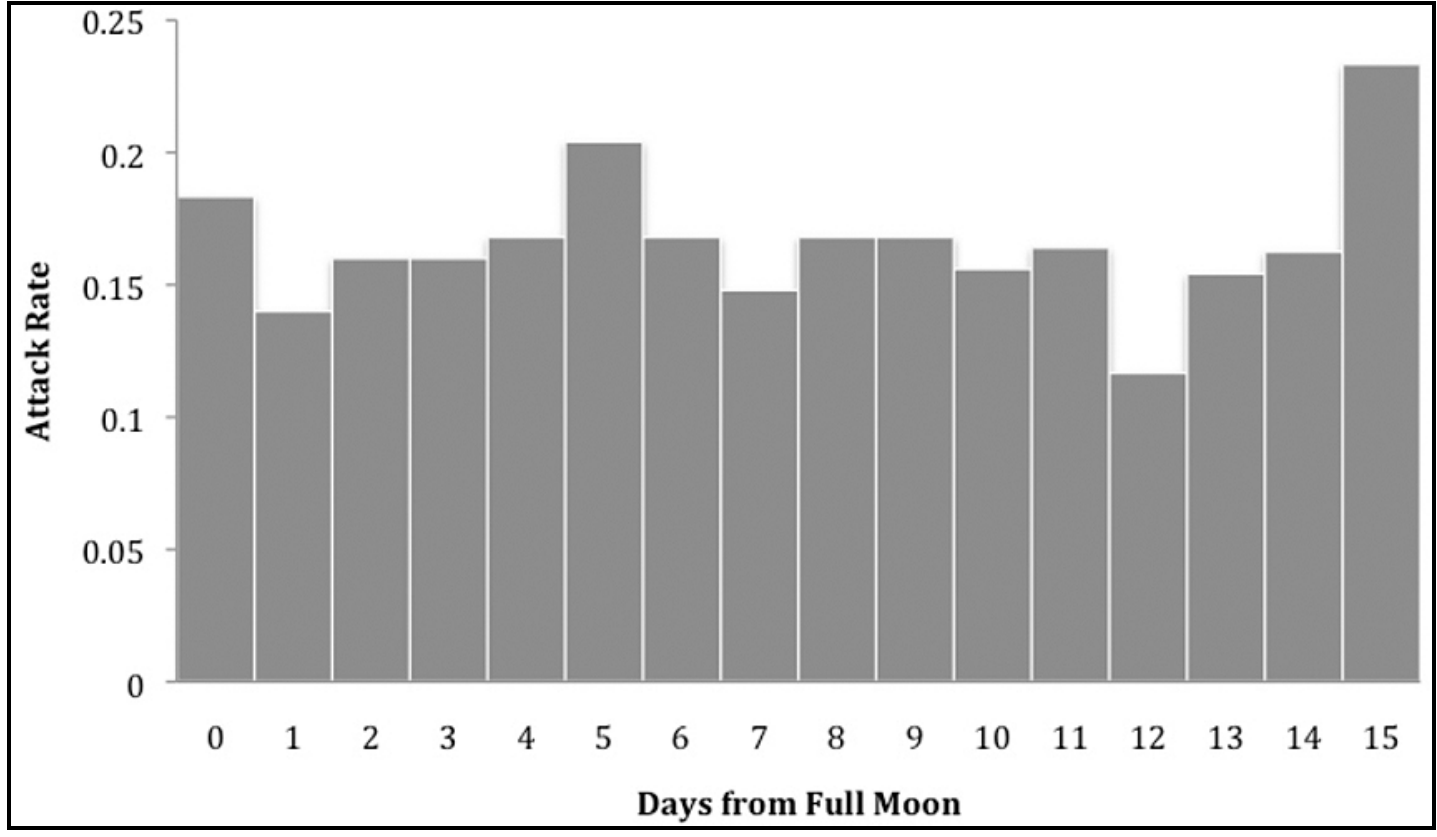

c) non-surfers

Fig. (1). (a, b, c) Shark attack rates around the nearest full and new moon.

to $\mathrm{Mf}$ and $\mathrm{Mn}$ but reappeared on day 5 and day 9 as well, indicating a cycle of some kind (Fig. 1a). Fig. (1b) representing surfers only also follows this cyclical effect around the same days. Although this cyclic patterns is less pronounced for non-surfers (Fig. 1c), it is still present as well. The multiple peaks on the graphs make it clear that Mf and 
Mn are not the only days on which shark attack rates were elevated; hence, the difference in the mean shark attack rates for $\mathrm{Mf}$ or $\mathrm{Mn}$ and the rest of the days of the lunar month is non-significant. Were Mf and Mn the only two peaking days for shark attack rates, then a significant difference would be shown in the results of the above test.

Although this analysis clearly refutes the claim that an increased rate of shark attacks occurs only during Mf or Mn, it evidently opens the door for research on a new problem, namely identifying the factors that trigger the cyclic effect seen in Fig. (1).

\section{CONCLUSION}

Finding triggering factors for shark attacks is important, and possibilities should be tested to defuse potentially dangerous situations before incidents occur [30,31]. However, even if a correlation appears likely, as shown here with the potential effects of lunar cycles, without proper testing, such an idea remains merely an anecdotal guess at best as shown by these results.

\section{CONFLICT OF INTEREST}

The authors confirm that this article content has no conflicts of interest.

\section{ACKNOWLEDGEMENTS}

Declared none.

\section{REFERENCES}

[1] Amin R, Ritter E, Cossette L. An investigation of shark density and attack rates in California. J Environ Ecol 2012a; 3: 246-55.

[2] Baldridge HD. Shark aggression against man: beginnings of an understanding. Calif Fish Game 1988; 74: 208-17.

[3] Nelson DR. Shark attack and repellency research: an overview. In: Zahuranec BJ, Ed. Shark repellents from the sea, new perspectives.. Washington: American Association for the Advancement of Science 1983; pp. 11-74.

[4] Laroche RK, Kocj AA, Dill LM, Oosthuizen WH Effects of provisioning ecotourism activity on the behaviour of white sharks Carcharodon carcharias. Mar Ecol Prog Ser 2007; 338: 199-209.

[5] Miller DJ, Collier RS. Shark attacks in California and Oregon, 1926-1979. Calif Fish Game 2004; 67: 76-104.

[6] Ritter E. Sharks-Mistaken identity? In: Bekoff M, Ed. Encyclopedia of Animal Behavior. vol 3. USA: Greenwood Press 2004; pp. 963-64.

[7] Cliff G, Dudley FSJ. Protection against shark attack in South Africa. Aust J Mar Fresh Res 1992; 43: 263-72.

[8] Ritter EK, Levine M. Use of forensic analysis to better understand shark attack behaviour. J Forens Odon-Stomatol 2004; 22: 40-6.

[9] Ritter EK, Levine M. Bite motivation of sharks reflected by the wound structure on humans. Am J Forensic Med Pathol 2005; 26: 136-40.

[10] Hazin F, Burgess G, Carvalho F. A shark attack outbreak off Recife, Pernambuco, Brazil, 1992-2006. Bull Mar Sci 2008; 82: 199212.

[11] ScienceDaily. Case study analyzes why, where and when of leading shark attack site. Available at: www.sciencedaily.com/rel- eases/2010/05/100526151535.htm.2010; [Accessed 1 December 2012].

[12] Cleeve D. Full moon blamed for shark attacks. msn news. Available at: http:// www.sciencedaily.com/releases/2010/05/100526151535.htm. 2011; [Accessed 1 December 2012].

[13] Hirji Z. Florida coast: hotspot for shark attacks. Discover News, Available at: http://news.discovery.com/animals/florida-coast-hotspot-for-shark-attack. 2001; [Accessed 1 December 2012].

[14] Olivera JC. Shark attacks spike on new moons - study. News.com.au. Available at: http://www.news.com.au/worldold/shark-attacks-spike-on-new-moons-study/story-e6frfkyi1225872458248. 2010; [Accessed 1 December 2012].

[15] Bhattacharjee C, Bradley P, Smith M, Scally A, Wilson B. Do animals bite more during a full moon? Retrospective observational analysis. BMJ 2000; 321: 1559-61.

[16] Horning M, Trillmich F. Lunar cycles in diel prey migrations exert a stronger effect on the diving of juveniles than adult Galapagos fur seals. Proc R Soc Lond B 1999; 266: 1127-32.

[17] Robertson D, Petersen C, Brawn J. Lunar reproductive cycles of benthic-brooding reef fishes: reflections of larval biology or adult biology? Ecol Monogr 1990; 60: 311-29.

[18] Cajochen C, Altanay-Eickel S, Münch M, Frey S, Knoblauch V, Wirz-Justice A. Evidence that the lunar cycle influences human sleep. Curr Biol 2013; 23: 1485-8.

[19] Foster R, Roenneberg T. Human responses to the geophysical daily, annual and lunar cycles. Am J Psychiatry 2008; 18: R784R794.

[20] Lieber A, Sherin C. Homicides and the lunar cycle: toward a theory of lunar influence on human emotional disturbance. Am J Psychiatry 1972; 129: 69-74.

[21] Lowry M, WIlliams D, Metti Y. Lunar landings-Relationship between lunar phase and catch rates for an Australian gamefishtournament fishery. Fish Res 2007; 88: 15-23.

[22] Poisson F, Gaertner J-C, Taquet M, Durbec, J-P, Bigelow K. Effects of lunar cycle and fishing operations on longline-caught pelagic fish: fishing performance, capture time, and survival of fish. Fish Bull 2010; 108: 268-81.

[23] Shepard ELC, Ahmed MZ, Southall EJ, Witt MJ, Metcalfe JD, Sims DW. Diel and tidal rhythms in diving behaviour of pelagic sharks identified by signal processing of archival tagging data. Mar Ecol Prog Ser 2006; 328: 205-13.

[24] Hammerschlag N, Martin RA, Fallows C. Effects of environmental conditions on predator-prey interactions between white sharks (Carcharodon carcharias) and Cape fur seals (Arctocephalus pusillus pusillus) at Seal Island, South Africa. Environ Biol Fish 2006; 76: 341-50.

[25] Trillmich F, Mohren W. Effects of the lunar cycle on the Galapagos fur seal Arctocephalus galapagoensis. Oecologia 1981; 48: 8592.

[26] Shark Research Institute. Global shark attack file, Incident log. Available at: www.sharkattackfile.net/incidentlog.htm. 2012; [Accessed 1 December 2012].

[27] Amin R, Ritter E, Cossette L. An investigation of shark density and attack rates in California. J Environ Ecol 2013; [in press].

[28] Amin R, Ritter E, Kennedy P. A geospatial analysis of shark attack rates for the East coast of Florida: 1994-2009. Mar Fresh Behav Physiol 2012; 45: 185-98

[29] Leeworthy VR, Wiley PC. Current participation patterns in marine recreation. Special Project National Oceanic and Atmospheric Administration, Silver Spring, Maryland 2000.

[30] Ritter E Shark-Human Interaction. Situations Findings Recommendations. SharkSchool Publishing, Pensacola 2012; 200p.

[31] Ritter EK, Amin RW. Effect of human body position on the swimming behavior of bull sharks, Carcharhinus leucas. Soc Anim 2012; 20: $225-35$. 